\title{
XVIII. New optical experiment
}

\section{Professor Airy}

To cite this article: Professor Airy (1831) XVIII. New optical experiment, Philosophical Magazine Series 2, 10:56, 141-143, DOI: $10.1080 / 14786443108675699$

To link to this article: http://dx.doi.org/10.1080/14786443108675699

曲 Published online: 10 Jul 2009.

Submit your article to this journal

III Article views: 1

Q View related articles $₫$ 
But it would be more accurate to solve the proposition by direct analysis; and writing this last equation as before,

$$
\Delta^{\prime} u=\frac{h^{\prime}}{h} \mathbf{A}+\frac{h^{\prime 2}}{h^{2}} \mathrm{~B}+\frac{h^{\prime 3}}{h^{\mathrm{s}}} \mathbf{C} \text {. }
$$

By reversing the series, we have

$$
\frac{h^{\prime}}{h}=\frac{\triangle^{\prime} u}{\mathbf{A}}-\left(\frac{\Delta^{\prime} u}{\mathbf{A}}\right)^{2} \frac{\mathbf{B}}{\mathbf{A}}+\left(\frac{\Delta^{\prime} u}{\mathbf{A}}\right)^{3}\left(\frac{2 \mathrm{~B}^{2}-\mathbf{A C}}{\mathrm{A}^{2}}\right)
$$

Remark.-The rule given in the Nautical Almanac is according to equation [1], but upon the supposition that the tables are not accurate beyond $\Delta^{2} u$, and consequently that $\triangle^{3} u$ ought to $b e=0$, and therefore $\frac{\Delta^{2} u+\Delta^{2} u_{1}}{2}$ is used instead of $\Delta^{2} u:$ thus

$$
u^{\prime}=u+\frac{h^{\prime}}{h} \Delta u+\frac{h^{\prime}\left(h^{\prime}-h\right)}{2 h^{2}}\left(\frac{\Delta^{2} u+\Delta^{2} u_{\mathrm{r}}}{2}\right) \text {; but now that }
$$

the tables are sufficiently accurate it would be better to use $\triangle^{z} u$.

And hence it seems to me that Mr. Baily has committed an oversight; for wishing to introduce $\triangle^{3} u$, he has still employed $\frac{\triangle^{2} u+\Delta^{2} u_{\mathrm{r}}}{2}$, which was used only on the supposition that $\Delta^{3} u$ ought to be neglected, and has written

$u^{\prime}=u+\frac{h^{\prime}}{h} \Delta u+\frac{h^{\prime}\left(h^{\prime}-h\right)}{2 h^{2}}\left(\frac{\Delta^{2} u+\Delta^{2} u_{1}}{2}\right)+\frac{h^{\prime}\left(h^{\prime}-h\right)\left(h^{\prime}-2 h\right)}{6 h^{3}} \Delta^{s} u$, corrected in the Errata to

$u^{\prime}=u+\frac{h^{\prime}}{h} \Delta u+\frac{h^{\prime}\left(h^{\prime}-h\right)}{2 h^{2}}\left(\frac{\Delta^{2} u+\Delta^{2} u_{1}}{2}\right)+\frac{h^{\prime}\left(h^{\prime}-h\right)\left(h^{\prime}-\frac{1}{2} h\right)}{6 h^{3}} \Delta^{3} u$ instead of equation [1].

XVIII. New Optical Experiment by Professor AIRY.

[We are indebted to the kindness of a Cambridge friend for the following account of some new optical experiments made by Professor Airy: it announces some remarkable discoveries, which have an important bearing in the verification of the undulatory theory of light.]

A $\mathrm{N}$ instructive variation of the experiment of Newton's co$A$ loured rings (suggested by the consideration of Fresnel's formulæ for the intensity of reflected vibrations) has lately been made by Professor Airy. When a lens is placed on a 
plane glass it is well known that a set of rings is seen whose centre is remarkably black: and it is indifferent whether common light or polarized light be used, the only difference made by the latter being that when the plane of polarization is perpendicular to the plane of reffection, and the angle of incidence is the polarizing angle, the rings disappear; but on altering the angle of incidence either way, the rings still appear with the centre black. If, however, a lens is placed on a metallic surface, and the incident light is polarized in the plane perpendicular to the plane of incidence; while the angle of incidence is small, the centre of the rings is black; when it is equal to the polarizing angle of the glass the rings disappear (though there is still copious reflection from the metal): then on the smallest increase of the angle of incidence the rings are seen with their centre white, and they continue so till the angle of incidence $=90^{\circ}$. It is indifferent whether the light is polarized before or after reflection; and a remarkable effect may be thus produced : if common light is incident at an angle greater than the polarizing angle, the rings have a dark centre; but on placing a plate of tourmaline (with its axis perpendicular to the plane of reflection) between the eye and the lens, the rings are seen with a bright centre. The Professor conceives that the whole of these experiments are in the highest degree favourable to the theory of undulations with transversal vibrations as given by Fresnel, and to the idea (which is a necessary part of that theory) that polarization is not a modification or physical change in the light, but a resolution of its vibrations into two sets, one in one plane, and the other in the plane perpendicular to the former, one of which sets sometimes is suppressed and sometimes describes a different path. The last experiment (where the character of the rings is changed after they are formed) appears almost decisive of this point. From the manner in which the rings alter when the tourmaline is turned, the Professor infers that the phases of the vibrations in the plane of reflection are more accelerated by reflection at metallic surfaces than those of the vibrations perpendicular to the plane of reflection. The dark centres, it is to be observed, are never so dark as when the lens is placed on glass; and the bright ones are never very bright.

The result of the following experiment, like those of the former, was anticipated by theoretical considerations, and shows the clearness with which, by Fresnel's theory, the effects of modifications can be traced whose very nature is inexpressible on any other theory. In the common polarizing apparatus, plane- 
plane-polarized light is incident, and the light emerging from the interposed crystal is resolved into two streams of planepolarized light (by the analysing plate), of which one only is transmitted to the eye. It is known that circularly or elliptically polarized light will, if incident on the crystal, form rings; but it has not been remarked as a general theorem, that rings will be visible if the analysing plate be so constructed as to resolve the light emerging from the crystal into any two lcinds of light, of which it suppresses one and transmits the other to the eye. Now by means of Fresnel's rhomb, or (imperfectly) by a film of mica, the analysing plate may be made to resolve the emergent light into two circularly-polarized rays, one of which it transmits to the eye, while the other is suppressed. Supposing the light to be thus analysed and supposing the incident light to be circularly polarized, theory gives this result: the tint will depend only on the gain or loss of the extraordinary on the ordinary ray: there will be no brushes: the appearances will not alter as the crystal is turned about the incident ray. These conclusions are completely supported by experiments on uniaxal and biaxal crystals and unannealed glass. Iceland spar, for instance, shows rings without brushes: nitre, \&c. exhibit the lemniscates in their whole extent without any interruption.

Cambridge, July 25, 1831.

\section{Proceedings of Learned Societies.}

\section{GEOLOGICAL SOCIETY.}

June 8th.- A LETTER was read, from Joshua Trimmer, Esq. A to the Rev. Dr. Buckland, V.P. G.S. "On the diluvial deposits of Caernarvonshire, between the Snowdon chain of hills and the Menai strait, and on the discovery of marine shells in diluvial sand and gravel on the summit of Moel Tryfane, near Caernarvon, $1000 \mathrm{ft}$ above the level of the sea."

The object of this paper is to point out evidences of extensive diluvial action in that part of Caernarvonshire which lies at and near the N.W. base of the mountains of Snowdonia. This district is traversed in a direction from N.E. to S.W, and nearly parallel to the mountain chain, by two remarkable beds of roofing slate, well known by the name of Penrhyn Slate, dipping usually to the S.E. at a considerable angle, and extending along a series of hills of moderate elevation, between the Snowdonian chain and the Menai strait. Great part of the surface of these hills, and of the still lower ground between them and the Menai, is so covered by accumulations of drifted gravel, sand and clay, that the slate is seldom accessible, without first quarrying 